Contributors: BL conceived the study, collected data, and contributed to the writing of the paper. KB collected data and contributed to the writing of the paper. $\mathrm{BL}$ will act as guarantor for the paper.

Funding: None.

Competing interests: None declared.

1 Reynell J. Language development and assessment. Lancaster: MTP, 1980.

2 Huntley M. The Griffiths mental development scales. From birth to 2 years. High Wycombe: Association for Research in Infant and Child Development, 1996.
3 Sheridan MD. From birth to five years. Children's developmental progress. Slough, Middlesex: National Foundation for Educational Research, 1997.

4 Baron-Cohen S, Cox A, Baird G, Swettenham J, Nightingale N, Morgan $\mathrm{K}$, et al. Psychological markers in the detection of autism in infancy in a large population. Br J Psychiatry 1996;168:158-63.

5 Bayley N. Bayley scales of infant development, 2nd ed. San Antonio: Harcourt Brace, 1993.

6 Frankenburg WK, Dodds J, Archer P, Shapiro H, Bresnick B. The Denver II: a major revision and restandardisation of the Denver developmental screening test. Pediatrics 1992;89:91-7.

\title{
Waiting times for cancer patients in England after general practitioners' referrals: retrospective national survey
}

\author{
Peter Spurgeon, Fred Barwell, David Kerr
}

\section{雨}

This paper was first posted on www.bmj.com on 13 March 2000

Health Services Management Centre, School of Public Policy, University of Birmingham, Park House, Birmingham B15 2RT

Peter Spurgeon professor of health services management Fred Barwell honorary research fellow

CRC Institute for Cancer Studies, Medical School, University of Birmingham, Birmingham B15 2TJ

David Kerr professor of clinical oncology

Correspondence to: P Spurgeon p.spurgeon@bham ac.uk

BMJ 2000;320:838-9
Britain fares rather badly in international comparisons of cancer patients' survival rates. Relative survival rates in England and Wales ${ }^{1}$ are generally lower than in Europe, ${ }^{2}$ which in turn are lower than rates in the United States. ${ }^{3}$ The differences between England and Wales and the rest of Western Europe in survival rates for colon cancer and female breast cancer arise primarily in the first six months after diagnosis, suggesting that these differences may relate to later presentation or delays in treatment for British patients.

Given this background, the government has pledged to "end waiting times for cancer surgery, thereby helping thousands of women waiting for breast cancer treatment." The assumption is that reduced waiting times will lead to more rapid diagnosis, earlier instigation of care, and reduced psychological morbidity. Indeed, the NHS has been asked to set a target of two weeks from referral by a general practitioner to first hospital outpatient appointment for all suspected cases of cancer.

In order to investigate the delays that British cancer patients face, we undertook a retrospective survey of patients with newly diagnosed cancer in October 1997.

\section{Subjects, methods, and results}

We invited all English acute hospital trusts (whether cancer centres or units) to submit relevant information on all new patients with a cancer diagnosis confirmed during October 1997. The data were collected during April and May 1998, allowing a tracking period of up to six months after diagnosis. We measured how long the patients were required to wait from their initial referral by their general practitioner for an outpatient appointment, for their first definitive treatment (when appropriate), and for any subsequent treatment.

Data returns were made by $218(98 \%)$ of the 223 trusts, representing 13454 patients. A greater proportion of patients who had been urgently referred by their general practitioner were seen within two weeks compared with those who were non-urgent referrals. However, the results clearly showed that there was substantial variation in patients' waiting times according to tumour type, whether the initial referral was coded urgent, and the region where treatment was undertaken. The table shows that waiting times for urgent appointments were significantly less than the waiting times for non-urgent appointments: this was so for all 10 types of cancer and for time from general practitioner referral to first definitive treatment as well as for time from referral to outpatient appointment.

Waiting times for cancer patients in England, from general practitioner referral to first outpatient appointment and to first definitive treatment (excluding referrals not by general practitioner)

\begin{tabular}{|c|c|c|c|c|}
\hline \multirow[b]{2}{*}{$\begin{array}{l}\text { Type of cancer } \\
\text { and urgency of } \\
\text { referral }\end{array}$} & \multicolumn{2}{|c|}{$\begin{array}{l}\text { Time to first outpatient } \\
\text { appointment (days) }\end{array}$} & \multicolumn{2}{|c|}{$\begin{array}{l}\text { Time to first definitive } \\
\text { treatment (days) }\end{array}$} \\
\hline & $\begin{array}{c}\text { Median } \\
\text { (interquartile } \\
\text { range) }\end{array}$ & $\begin{array}{l}\text { When } 90 \% \\
\text { of patients } \\
\text { seen }\end{array}$ & $\begin{array}{c}\text { Median } \\
\text { (interquartile } \\
\text { range) }\end{array}$ & $\begin{array}{c}\text { When } 90 \% \\
\text { of patients } \\
\text { seen }\end{array}$ \\
\hline \multicolumn{5}{|l|}{ Breast $(n=1517)$ : } \\
\hline Urgent & $9(4-15)$ & 22 & $27(15-41)$ & 62 \\
\hline Non-urgent & $14(8-21)$ & 29 & $35(21-57)$ & 90 \\
\hline \multicolumn{5}{|c|}{ Colorectal $(n=1023)$ : } \\
\hline Urgent & $13(6-21)$ & 35 & $39(21-64)$ & 95 \\
\hline Non-urgent & $27(16-43)$ & 60 & $72(44-104)$ & 147 \\
\hline \multicolumn{5}{|l|}{ Lung $(n=767)$ : } \\
\hline Urgent & $7(3-13)$ & 21 & $39(21-61)$ & 91 \\
\hline Non-urgent & $12(7-22)$ & 33 & $47(28-77)$ & 112 \\
\hline \multicolumn{5}{|l|}{ Ovary $(n=189)$ : } \\
\hline Urgent & $6(1-14)$ & 23 & $21(14-40)$ & 64 \\
\hline Non-urgent & $24(7-32)$ & 39 & $45(18-77)$ & 116 \\
\hline \multicolumn{5}{|l|}{ Cervix $(n=321)$ : } \\
\hline Urgent & $22(10-34)$ & 58 & $46(28-79)$ & 123 \\
\hline Non-urgent & $41(27-65)$ & 93 & $75(44-119)$ & 181 \\
\hline \multicolumn{5}{|l|}{ Uterus $(n=223)$ : } \\
\hline Urgent & $19(9-29)$ & 39 & $47(24-83)$ & 114 \\
\hline Non-urgent & $29(19-41)$ & 55 & $73(50-122)$ & 163 \\
\hline \multicolumn{5}{|l|}{ Prostate $(n=677)$ : } \\
\hline Urgent & $19(9-29)$ & 44 & $53(26-91)$ & 143 \\
\hline Non-urgent & $41(23-56)$ & 77 & $111(64-183)$ & 292 \\
\hline \multicolumn{5}{|l|}{ Bladder ( $n=627)$ : } \\
\hline Urgent & $20(7-32)$ & 48 & $57(28-84)$ & 124 \\
\hline Non-urgent & $33(21-57)$ & 70 & $82(56-119)$ & 178 \\
\hline \multicolumn{5}{|l|}{ Stomach $(n=241)$ : } \\
\hline Urgent & $10(4-22)$ & 36 & $42(21-73)$ & 112 \\
\hline Non-urgent & $27(18-50)$ & 70 & $75(36-100)$ & 150 \\
\hline \multicolumn{5}{|c|}{ Oesophagus $(\mathrm{n}=249)$ : } \\
\hline Urgent & $11(5-21)$ & 33 & $44(24-63)$ & 85 \\
\hline Non-urgent & $24(13-35)$ & 57 & $65(37-112)$ & 154 \\
\hline
\end{tabular}




\section{Discussion}

The underlying causes of the variation in waiting times observed here are not explained by the audit data, and we do not suggest that there are "across the board" implications for clinical outcome in the waiting times reported. Clearly, these are clinical issues and would vary with specific types of cancer. However, the focus on reducing unnecessary delays in cancer treatment stems from the belief that the earlier disease is detected, the more quickly multidisciplinary care can be instigated and the better the outcome. Irrespective of the specific waiting times reported here, the key contribution of this study is in establishing baseline data which can be used to set targets for improvement and, crucially, to monitor such attempts.
We thank Dr Stephen Green for his advice on the development of the guidance notes used by the trusts in completing the survey instrument and the many trust staff who gave their time in the collection of the data.

Contributors: PS coordinated the study and helped design the survey instrument and write the report. FB analysed the data and helped write the report. DK helped initiate the research, interpret the data, and write the report.

Funding: The study was funded by the Department of Health (HSC1998/999)

Competing interests: None declared.

1 Coleman MP, Babb P, Damiecki P, Grosclaude P, Honjo S, Jones J, et al. Cancer survival trends in England and Wales 1971-1995: deprivation and NHS region. London: Stationery Office, 1999.

2 Berrino F, Capocaccia R, Estéve J, Gatta G, Hakulinen T, Micheli A, et al Survival of cancer patients in Europe: the EUROCARE study II. Lyons: IARC 1999. (IARC Scientific Publication No 151.)

3 National Cancer Institute. SEER Stat-cancer incidence public use database 1973-95. Release 1.1. Bethesda MD: NCI, 1998.

(Accepted 2 March 2000)

\title{
Relation between infants' birth weight and mothers' mortality: prospective observational study
}

\author{
George Davey Smith, Seeromanie Harding, Michael Rosato
}

Several studies have shown inverse associations between birth weight and incidence of cardiovascular disease in adulthood, ${ }^{2}$ suggesting that development in early life may influence the risk of disease many years later. The existence of intergenerational influences on birth weight, illustrated by correlations between the birth weight of parents and the birth weight of their offspring, suggests that birth weight of offspring should be associated with the risk of mortality from cardiovascular disease among parents. So far only one small study has investigated this possibility. ${ }^{3}$ In that study each kilogram decrease in birth weight of the infant was associated with a doubling in the risk of parental mortality from cardiovascular disease. We have replicated this potentially important finding in the Office for National Statistics' longitudinal study, a follow up of $1 \%$ of the population of England and Wales from the 1971 census. $^{4}$

\section{Methods and results}

In the longitudinal study, information from birth registrations of infants during 1976-97 is linked to data from the census and death registration (1976-97) for study members. Birth weight was collected from 1976 onwards, but during the 1970 s the data were not complete. The first recorded birth weight of infants to 44813 women aged 15-45 years at birth registration was used as the exposure measure. Mean birth weight was $3210 \mathrm{~g}$ (SD $566 \mathrm{~g}$ ). The average birth weight changed little over the study period ( $4.6 \mathrm{~g}$ increase a year, $95 \%$ confidence intervals $3.6 \mathrm{~g}$ to $5.6 \mathrm{~g}$ ). The difference between average male birth weight and average female birth weight $(99 \mathrm{~g})$ was subtracted from each male birth weight. Socioeconomic position (housing tenure and car access) of mothers was taken from the 1971 census.
Mortality was analysed by using Cox's proportional hazards model in relation to birth weight, with adjustment for socioeconomic position and whether the birth occurred inside or outside marriage (with additional adjustment for sole registration or joint registration if outside marriage).

The table shows a substantial association between infants' birth weight and mothers' mortality from all causes and from cardiovascular disease. The relative risk of maternal cardiovascular mortality associated with a $1 \mathrm{~kg}$ lower birth weight in offspring was closely similar to that seen in the previous study of this issue (2.00 (1.18 to 3.33$\left.)^{3}\right)$; the corresponding associated risks for the other two major causes of death (153 deaths from cancer (1.33; 1.03 to 1.72$)$ and 38 accidental or violent deaths (1.06; 0.61 to 1.85$)$ ) were considerably smaller than those for cardiovascular mortality.

Department of Social Medicine, University of Bristol, Canynge Hall, Bristol BS8 2PR

George Davey Smith professor of clinical epidemiology

Office for National Statistics, London SW1V 2QQ

Seeromanie

Harding senior research officer Michael Rosato senior research officer

Correspondence to: G Davey Smith zetkin@bristol.ac.uk

BMJ 2000;320:839-40

\section{Comment}

We found a strong inverse relation between infants' birth weights and mothers' mortality from cardio-

Infants' birth weight and mothers' mortality, 1976-97, according to data from Office for National Statistics' longitudinal study (England and Wales). Values are hazard ratios (95\% confidence interval) unless stated otherwise

\begin{tabular}{lccc} 
& No of & \multicolumn{2}{c}{ Deaths of mothers } \\
\cline { 3 - 4 } Infants' birth weight $(\mathbf{g})$ & $\mathbf{b i r t h s}$ & $\begin{array}{c}\text { From all causes } \\
(\mathbf{n = 2 9 3 )}\end{array}$ & $\begin{array}{c}\text { From cardiovascular disease } \\
(\mathbf{n}=\mathbf{4 1})\end{array}$ \\
\hline$<2500$ & 3891 & $3.06(2.15$ to 4.35$)$ & $7.05(2.64$ to 18.77$)$ \\
\hline $2500-3499$ & 27360 & $1.27(0.96$ to 1.69$)$ & $1.96(0.80$ to 4.82$)$ \\
\hline$\geqslant 3500$ & 13562 & 1.00 & 1.00 \\
\hline Per $1000 \mathrm{~g}$ & & $1.63(1.37$ to 1.94$)$ & $2.25(1.48$ to 3.41$)$ \\
\hline Per $1000 \mathrm{~g} \mathrm{(adjusted)}{ }^{*}$ & & $1.61(1.35$ to 1.92$)$ & $2.22(1.46$ to 3.38$)$ \\
\hline
\end{tabular}

*Adjusted for socioeconomic position (housing tenure and car access) at the start of the study in 1971 and marital status (sole or joint registration if unmarried) at birth registration.

Crown copyright reserved. 